\title{
É Possível Ensinar Estocástica para Crianças da Educação Infantil? Uma Análise à Luz da Teoria de Bruner
}

\author{
Is it Possible to Teach Stochastics to Children in Childhood \\ Education? An Analysis Based on Bruner's Theory
}

Cristiane de Fátima Budek Dias*

ORCID iD 0000-0003-0376-0905

Caroline Subirá Pereira ${ }^{* *}$

ORCID iD 0000-0003-1432-3612

Juliane Budek Dias ${ }^{* * *}$

ORCID iD 0000-0002-2721-5074

Guataçara dos Santos Junior $^{* * * *}$

ORCID iD 0000-0002-6234-7961

Nilcéia Aparecida Maciel Pinheiro ${ }^{* * * *}$

ORCID iD 0000-0003-3313-1472

Awdry Feisser Miquelin ${ }^{* * * * * *}$

ORCID iD 0000-0002-7459-3780

\footnotetext{
* Mestra em Ensino de Ciência e Tecnologia pela Universidade Tecnológica Federal do Paraná (UTFPR). Docente na Faculdade Educacional da Lapa (FAEL), Lapa, Paraná, Brasil. Endereço para correspondência: Rua Doutor Washington Subtil Chueire, 330, Jardim Carvalho, Ponta Grossa, Paraná, Brasil, CEP: 84017-220. Email: cristianed@alunos.utfpr.edu.br.

** Mestra em Ensino de Ciência e Tecnologia pela Universidade Tecnológica Federal do Paraná (UTFPR). Docente na Faculdade Educacional da Lapa (FAEL), Lapa, Paraná, Brasil. Endereço para correspondência: Rua Doutor Washington Subtil Chueire, 330, Jardim Carvalho, Ponta Grossa, Paraná, Brasil, CEP: 84017-220. Email: carolinepereira@alunos.utfpr.edu.br.

*** Especialista em Educação Infantil pelo Centro Universitário e Faculdade Educacional Araucária (UNIFACEAR). Docente da rede pública de ensino do município de Araucária, Paraná, Brasil. Endereço para correspondência: Rua Guadalajara, 468, Apto 102, Centro, Araucária, Paraná, Brasil, CEP: 83702-110. E-mail: julibudekdias@hotmail.com.

**** Doutor em Ciências Geodésias pela Universidade Federal do Paraná (UFPR). Docente na Universidade Tecnológica Federal do Paraná (UTFPR). Endereço para correspondência: Rua Doutor Washington Subtil Chueire, 330, Jardim Carvalho, Ponta Grossa, Paraná, Brasil, CEP: 84017-220. E-mail: guata@utfpr.edu.br.

***** Doutora em Educação Científica e Tecnólogica pela Universidade Federal de Santa Catarina (UFSC). Docente na Universidade Tecnológica Federal do Paraná (UTFPR) . Endereço para correspondência: Rua Doutor Washington Subtil Chueire, 330, Jardim Carvalho, Ponta Grossa, Paraná, Brasil, CEP: 84017-220. E-mail: nilceiaamp@gmail.com.

******* Doutor em em Educação Científica e Tecnólogica pela Universidade Federal de Santa Catarina (UFSC). Docente na Universidade Tecnológica Federal do Paraná (UTFPR) . Endereço para correspondência: Rua Doutor Washington Subtil Chueire, 330, Jardim Carvalho, Ponta Grossa, Paraná, Brasil, CEP: 84017-220. E-mail: awdryfei@gmail.com.
} 


\title{
Resumo
}

Conceitos estocásticos são considerados complexos para serem ensinados para crianças, porém são importantes para a atuação cotidiana e demandam tempo para o desenvolvimento. Neste sentido, este artigo tem como objetivo analisar as contribuições de uma prática pedagógica, desenvolvida para ensinar Estocástica, a crianças da Educação Infantil, à luz da teoria de ensino de Bruner. A prática foi aplicada em duas turmas de Educação Infantil, compreendendo a faixa etária de 3 a 5 anos. Os dados foram coletados por meio de gravações de vídeo, registros fotográficos e de narrativa da professora das turmas. Para a análise, optou-se pela metodologia da Análise Textual Discursiva. Os resultados sugerem que a prática contribuiu para o avanço no desenvolvimento intelectual das crianças, possibilitou a aprendizagem por descoberta, atendeu a todas as crianças e auxiliou na formação de conceitos estocásticos.

Palavras-chave: Ensino de Estocástica. Teoria de Ensino de Bruner. Ensino de forma honesta. Aprendizagem por descoberta.

\begin{abstract}
Stochastic concepts are a complex issue to be taught to children, however it is an important subject in everyday practice and requires a continual development through time. In this sense, this paper aims to analyze the contributions of a pedagogical practice developed on Stochastic education in early childhood education using Bruner's theory of education. This pedagogical practice was used in two classes in the age group of 3-5 years. Several data were collected through textual, photographs, and video recordings. The textual data were retrieved from teachers' narrative inquiry. The analysis was performed through the Discursive Textual Analysis methodology. The results suggest that the pedagogical practice lead to an advance in the children's intellectual development, enabling their learning through discovery, reaching all children, and promoting their development of stochastic concepts.
\end{abstract}

Keywords: Stochastic Education. Bruner's Theory of Education. Honesty in education. Discovery learning.

\section{Introdução}

Este artigo tem como ponto de partida a seguinte pergunta: É possível ensinar Estocástica na Educação Infantil? Deste questionamento é importante esclarecer que Estocástica refere-se ao termo empregado para desenvolver a combinatória, a estatística e a probabilidade de maneira simultânea.

Ensinar Estocástica para crianças da primeira etapa ${ }^{1}$ da Educação Básica pode parecer, ao menos a princípio, inacessível. As equações matemáticas e os conceitos envolvidos nos conteúdos da Estocástica seriam um obstáculo para efetivar a aprendizagem devido ao nível de abstração na qual são consideradas e, infelizmente, tratadas nos demais níveis de ensino.

Porém, a teoria da aprendizagem de Bruner argumenta que é possível ensinar qualquer conteúdo, desde que seja de uma maneira honesta, a qualquer criança em qualquer idade. Além disso, conceitos matemáticos, como os da Estocástica, precisam ser abordados desde

\footnotetext{
${ }^{1}$ Conforme as Diretrizes Municipais de Educação de Araucária, município em que o estudo foi desenvolvido, a primeira etapa da Educação Básica envolve crianças de 0 a 5 (ARAUCÁRIA, 2012).
} 
cedo para a construção do alicerce dos conceitos fundamentais, que permitam à criança progredir na transferência da aprendizagem (BRUNER, 1987).

Destarte, nesta perspectiva, o objetivo deste artigo é analisar as contribuições de uma prática pedagógica, desenvolvida para ensinar Estocástica, às crianças da Educação Infantil, à luz da teoria de ensino de Bruner.

A referida prática pedagógica foi aplicada no município de Araucária, Paraná, Brasil, em um Centro Municipal de Educação Infantil (CMEI). A aplicação ocorreu em duas turmas distintas, sendo uma com 08 crianças, e outra com 09 crianças, em ambas a faixa etária corresponde entre 3 e 5 anos de idade. Os dados foram coletados por meio de gravações de vídeo, registros fotográficos e de narrativa da professora das turmas. Para a análise, optou-se pela metodologia da Análise Textual Discursiva, com base em Moraes e Galiazzi (2016).

\section{Estocástica na Educação Infantil}

A Educação Infantil é a etapa inicial da Educação Básica, assim, é o primeiro contato da criança com a educação formal. O papel da escola, com as crianças inseridas nesta etapa, se consolida entre o cuidar e o educar, que são indissociáveis, e, nesta tarefa é importante que suas vivências e conhecimentos sejam considerados. A escola precisa, então, trabalhar no sentido de "ampliar o universo de experiências, conhecimentos e habilidades dessas crianças, diversificando e consolidando novas aprendizagens [...]" (BRASIL, 2017, p. 34).

Ademais, as crianças vivem em um mundo permeado de diferentes espaços, tempos, fenômenos naturais e sociais e, nesta vivência, encontram com frequência conhecimentos matemáticos que aguçam a curiosidade delas (BRASIL, 2017). Destarte, é necessário efetivar práticas para a promoção de experiências que oportunizem às crianças realizar "observações, manipular objetos, investigar e explorar seu entorno, levantar hipóteses e consultar fontes de informação para buscar respostas às suas curiosidades e indagações” (BRASIL, 2017, p. 41).

Em relação aos conhecimentos matemáticos, nas turmas de Educação Infantil, que compreendem a faixa etária de 3 a 5 anos, o trabalho com os conteúdos deve promover o desenvolvimento cognitivo, a apropriação dos conhecimentos científicos e o processo de formação de conceitos (ARAUCÁRIA, 2012). Desta forma, é importante que haja oportunidade para que as crianças possam explorar as diferentes linguagens ao passo que se desenvolvem integralmente.

Neste sentido, a construção de diversos conceitos deve ser oportunizada, inclusive aqueles do campo da Estocástica. Vale lembrar que, no cotidiano, a criança já toma decisões e 
faz escolhas que dependem de pensamento e raciocínio estocásticos, assim, já possui noções sobre as quais novos conhecimentos podem emergir e ser aprofundados, ou seja, já é dotada de conhecimentos prévios que serão a base para a construção de novos conceitos.

As Diretrizes Curriculares Municipais de Araucária (DCMA) para a Educação Infantil possuem um eixo específico que trata dos conteúdos de estatística, probabilidade e combinatória: o eixo Tratamento da Informação. O documento aponta, dentro deste eixo, que a abordagem da Estocástica deve ser iniciada por meio da ludicidade e de práticas atrativas à criança, de acordo com sua realidade (ARAUCÁRIA, 2012).

Um ponto importante a ser considerado, e que está explícito no documento do município, é que, na Educação Infantil, o trato destes conceitos deve estar voltado a oportunizar uma introdução sobre os mesmos, pois o aprofundamento deve ser gradativo nas demais etapas educativas (ARAUCÁRIA, 2012).

Vale destacar que, mesmo que seja uma iniciação à Estocástica, o trabalho com esse eixo faz parte de um propósito maior: "dar condições para que essas crianças organizem e compreendam com maior propriedade o mundo que as cerca, do mesmo modo em que favorece o envolvimento na construção de tabelas e gráficos como maneiras de organizar as informações por elas observadas" (NOGUEIRA; MARQUES, 2016, p. 4). E ainda é fundamental ter em mente que:

\begin{abstract}
Por serem formas mais complexas de pensamento, que envolvem raciocínios hipotético-dedutivos, defende-se que quanto mais cedo os conceitos envolvidos nessas formas de pensamento forem abordados na escola, mais oportunidades as crianças terão de refletir sobre os mesmos, pensarem e repensarem as ideias intuitivas que possuem e de avançarem em seus modos de raciocinar (BORBA, 2016, p. 2).
\end{abstract}

Entende-se, então, que a abordagem dos conceitos estocásticos, dentro da Educação Infantil, pode contribuir com o progresso da formação crítica do aluno, tendo em vista que são esses conceitos que influenciam diretamente no desenvolvimento do pensamento, raciocínio e na tomada de decisões.

Não se trata, porém, de trazer para o espaço da Educação Infantil atividades que requerem raciocínios para além daqueles adequados à sua fase de desenvolvimento, pois uma atenção especial deve ser dada para as metodologias a serem empregadas. Sobre este assunto, Borba (2016) afirma que:

[...] na Educação Infantil, é possível abordar noções e subconstrutos mais simples de alguns conceitos, a partir de situações práticas e lúdicas. Assim, as crianças, desde novas, podem ser estimuladas a pensarem em questões interessantes de investigação e como informações podem ser levantadas, organizadas, classificadas e interpretadas, bem como podem ser incentivadas a refletirem sobre como eventos ocorrem - de modo aleatório, previsível ou determinístico. Também, desde cedo, podem ser incentivadas a levantarem possibilidades de eventos ocorrerem e a 
enumerarem modos de elementos constituintes de uma situação serem combinados entre si (p. 2).

As metodologias, portanto, devem ser direcionadas e adaptadas em conformidade com a etapa de desenvolvimento intelectual das crianças, isso reafirma o pressuposto de que as atividades e os materiais precisam considerar a criança e sua realidade, bem como, as oportunidades de criação e exploração.

Lopes (2012, p. 165) argumenta sobre a relevância da "realização de experimentos que envolvem a aleatoriedade e estimativas. A vivência de coletar, representar e analisar dados que sejam significativos e inseridos no seu contexto pode ampliar seu universo de competências e acentuar seu potencial criativo".

Mobilizar o raciocínio e pensamento de crianças de 3 a 5 anos para o desenvolvimento de conceitos introdutórios da Estocástica é uma possibilidade para Fonseca e Estevam (2014), porém eles destacam que a prática de ensino deve priorizar alguns pontos: (i) ouvir e demonstrar que ela é ouvida; (ii) priorizar atividades curtas; (iii) diversificar as tarefas; (iv) questionar e socializar as ideias individualmente e em pequenos grupos; e (v) interações constantes com as crianças, para que se consiga observar se há indícios de aprendizagem.

Fonseca e Estevam (2014), além das recomendações de prática, citadas acima, incentivam o uso de material manipulativo para a realização das atividades, e este tipo de material também é indicado por Borba (2016), como sendo de grande valia para tratar dos conteúdos que envolvem conceitos estocásticos com crianças.

Considera-se que estes materiais fazem parte da cultura infantil, por isso é importante que as práticas sejam desenvolvidas ludicamente e de maneira a colocar a criança para explorar as situações. A utilização destes recursos facilita a aprendizagem, pois, por meio deles, é possível que as crianças relacionem o conteúdo abstrato com o concreto e ainda reconheçam a aplicabilidade dos conceitos que estão sendo trabalhados (Pereira, 2017).

Ao refletir sobre a realidade da Educação Infantil, Lopes (2012, p. 167) enfatiza que "Esse aprendizado começa com brincadeiras em que o aluno aprende a criar significações, comunicar-se com outros, tomar decisões, decodificar regras, expressar a linguagem e socializar". Desta forma, o universo infantil deve ser respeitado a fim de que as tarefas propostas às crianças permitam que elas explorem e encontrem caminhos para seu próprio desenvolvimento. Este é o caminho apontado por Bruner (1969), em sua teoria de ensino que será esclarecida, mesmo que de modo sucinto, na próxima seção. 


\section{A teoria de ensino de Bruner}

Jerome Bruner (1915-2016) é autor de uma teoria de ensino rica em detalhes, porém, neste artigo, apresenta-se uma síntese. Para um conhecimento mais aprofundado da teoria recomenda-se buscar os textos originais do autor utilizados e citados neste artigo.

A teoria de Bruner parte da hipótese de que é possível ensinar qualquer assunto, de uma maneira honesta, a qualquer criança em qualquer estágio de desenvolvimento (BRUNER, 1987). Porém, quanto a esta afirmação, é importante esclarecer que Bruner não quis dizer que qualquer assunto poderia ser ensinado na sua forma final e formal, e sim que se levasse em conta a etapa do desenvolvimento intelectual em que se está o indivíduo.

Para Bruner (1969, p. 51) "há uma versão de cada conhecimento ou técnica apropriada para ensinar a cada idade, por mais introdutória que seja", sendo que o esforço seria o de representar a estrutura de cada conteúdo do modo como a criança visualiza o meio ao seu redor (BRUNER, 1987).

Bruner (1969) definiu três fases internas do desenvolvimento intelectual:

$1^{\text {a) }}$ Representação Ativa: consiste na capacidade de estabelecer relações entre a experiência do indivíduo e suas ações. Esta fase é característica das crianças em fase da préescola, que geralmente possuem interesse em manipular coisas por meio de suas ações.

$2^{\mathrm{a}}$ ) Representação Icônica: a criança é capaz de efetuar resolução de problemas em sua mente, manipular mentalmente alguns símbolos que para ela já tem significados (representam coisas e relações). Entretanto o poder simbólico (capacidade de obter símbolos para representar coisas) é limitado.

$3^{\mathrm{a}}$ ) Representação Simbólica: geralmente atinge as crianças a partir dos 10 anos e, nesta fase, elas são capazes de atingir novas variáveis em processos mentais e se tornam aptas a expressar suas soluções de problemas de forma mais formal e rigorosa.

Bruner (1987) ainda afirma que não se trata de uma estrutura estanque de desenvolvimento intelectual, visto que pode sofrer influências do meio, então o professor pode propor diferentes atividades que desafiem a criança e a façam avançar em seu desenvolvimento. Nota-se aqui a relevância de se colocar o assunto, ou corpo de conhecimento, de maneira apropriada, passando da representação ativa (ações) para a icônica (imagens) e, finalmente, para a simbólica (códigos). Assim, parte-se das ideias mais simples do conceito para as mais complexas (BRUNER, 1969). Neste sentido, o currículo deveria ser pensando em formato espiral, ou seja, de modo que o mesmo tópico pudesse ser visto várias vezes, mas em diferentes níveis de abstração e profundidade e de várias maneiras de 
representação.

Bruner (1969) reitera a necessidade de que os conhecimentos sejam tratados desde o princípio para que possam ser compreendidos pelas crianças e haja o domínio do conceito na posterioridade. Assim, afirma que "O mais importante no ensino de conceitos básicos é ajudar a criança a passar progressivamente do pensamento concreto à utilização de modos de pensamento conceptualmente mais adequados" (BRUNER, 1987, p. 36).

Os assuntos devem ser estruturados de maneira que possam ser mais facilmente compreendidos pelos estudantes, facilitando a rememoração (memória), a compreensão de princípios fundamentais para a transferência de aprendizagem e o reexame dos conceitos (avanço do conhecimento/assunto). A estrutura de um conteúdo envolve três princípios básicos (relacionados à habilidade para o domínio do assunto): forma da representação utilizada, envolvendo representações ativa, icônica e simbólica; economia, respeitando um equilíbrio da quantidade de informação a ser processada; potência efetiva, que envolve a capacidade do aluno de relacionar assuntos distintos e de enfrentar tarefas intelectuais (BRUNER, 1969).

E ainda, sobre a tarefa de ensinar, Bruner (1969) destaca a importância do processo da descoberta por meio da exploração de alternativas para efetivação do ensino, sendo que a instrução deve agir como facilitadora e organizadora deste processo. Embora Bruner (1969) enfatize a aprendizagem pela descoberta, acredita que isto deve ser feito de modo dirigido, na tentativa de impedir que a exploração de alternativas gere angústia ou confusão na criança. Porém, é importante destacar que o modo dirigido não deve ser visto como uma receita de bolo, e sim como algo planejado e estruturado.

Desta forma, o direcionamento das ações para a exploração de alternativas pela criança deve seguir no sentido de ativar, manter e dirigir a exploração, "algo que a faça ter início, algo que a mantenha em ação, e alguma coisa para evitar que se perca [...]" (BRUNER, 1969, p. 59). A ativação ocorre pela curiosidade, a manutenção pelo estabelecimento de instruções e a direção pelos objetivos. Assim, a aprendizagem por descoberta se efetiva com a direção da instrução, para que as explorações sejam realizadas de forma organizada e clara, dando ao estudante o direcionamento para a solução de problemas (BRUNER, 1969).

Ao citar estudos com foco em conceitos matemáticos que buscaram organizar o ensino desta forma, Bruner (1969) relata sobre o início da exploração das crianças até o processo final de representação abstrata do conceito, partindo-se de materiais manipuláveis, e construção de uma representação do conceito em imagens (produto do conceito) para, posteriormente, chegar a representação simbólica do conceito. 
Assim, revela que é "necessário à criança que aprende matemática ter, não só um sentido firme da abstração subjacente a sua tarefa, mas também uma boa coleção de imagens para ilustrá-la; sem tal coleção é difícil achar correspondências e verificar o trabalho simbólico" (BRUNER, 1969, p. 83).

A instrução, ou ensino, deve, então, possibilitar a descoberta, a exploração e a progressão do aluno nas diferentes fases de seu desenvolvimento intelectual, pois, de acordo com Bruner (1987), instruir o estudante em determinado conteúdo "não é levá-lo a armazenar resultados na mente, e sim ensiná-lo a participar do processo que torna possível a obtenção do conhecimento [...]", pois o ensino deve ser compreendido como processo, e não como produto (BRUNER, 1987, p. 89).

Tendo em vista as ideias apresentadas na teoria de Bruner e os conceitos fundamentais da Estocástica é que se organizou a proposta de atividade para as crianças da Educação Infantil, que está explicitada na próxima seção.

\section{Procedimentos metodológicos}

O estudo aqui apresentado possui abordagem qualitativa. De acordo com Silveira e Córdova (2009, p. 31), pesquisas qualitativas não se concentram na "representatividade numérica, mas sim, com aprofundamento da compreensão de um grupo social, de uma organização, etc". Desta maneira, os dados deste estudo não são mensuráveis numericamente e a preocupação está voltada para o aprofundamento da compreensão sobre o processo de ensino de Estocástica na Educação Infantil.

A pesquisa se deu em duas turmas distintas, uma com 8 (oito) crianças e outra com 9 (nove) crianças, em uma instituição de Educação Infantil da rede pública do município de Araucária, Paraná, Brasil. A faixa etária das crianças compreende entre 3 (três) e 5 (cinco) anos. A escolha do local de aplicação se deu por pertencer a um município que possui as diretrizes curriculares com eixo específico para Estocástica, conforme foi apontado no referencial teórico.

As atividades propostas foram aplicadas em três dias de aula, com total de 12 horas, e foram organizadas em cinco momentos. O primeiro momento das aulas consistiu em motivar, de alguma forma, a convivência das crianças com um (a) boneco (a) de E.V.A. O (a) boneco (a) deveria receber um nome conforme escolha das crianças. E, para efetivar esta nomeação, sugeriu-se uma votação, a qual foi sendo transcrita para um gráfico de barras.

Durante a aplicação, as crianças acompanharam todo o processo da construção do 
gráfico referente a escolha do nome, e cada uma delas participou do preenchimento do gráfico de acordo com a votação que fazia, conforme Figura 1 e 2 . A princípio, cada turma escolheu três nomes distintos de forma conjunta, e posteriormente cada criança votou no nome de sua preferência.

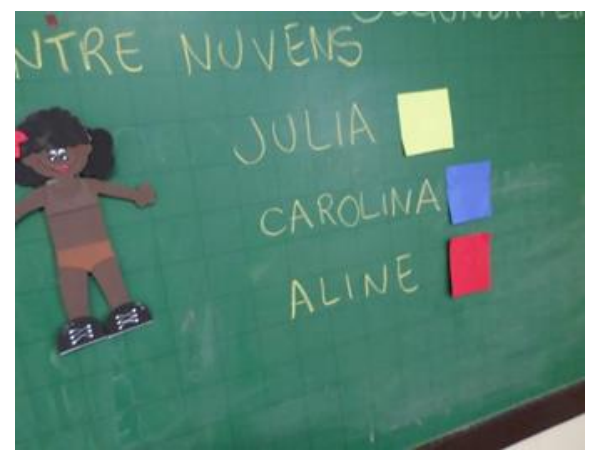

Figura 1 - Nomes sugeridos pela turma. Fonte: Dados da pesquisa, 2018.

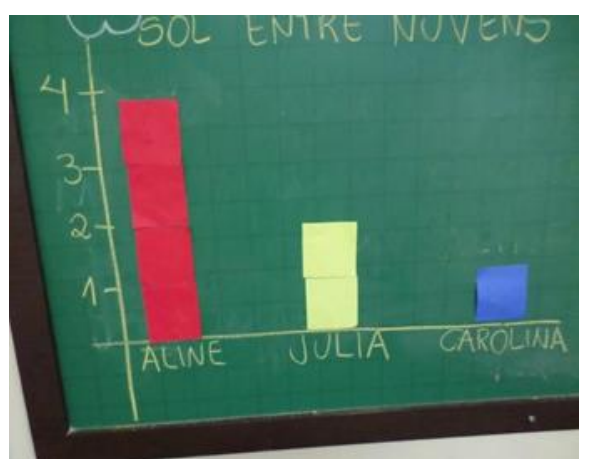

Figura 2 - Gráfico construído pela turma Fonte: Dados da pesquisa, 2018.

O segundo momento consistiu em trabalhar a interpretação do gráfico. Para tanto, a professora da turma questionou as crianças sobre o nome vencedor e solicitava, oralmente, uma justificativa de cada criança, incentivando cada uma na compreensão e leitura do gráfico que foi construído.

Feito isso, no terceiro momento, após o (a) boneco (a) já possuir um nome, a professora apresentou às crianças o "guarda-roupa" (opções de roupas) do (a) boneco (a), que era constituído por 3 (três) camisetas nas cores primárias (vermelha, amarela e azul) e 3 (três) bermudas nas cores secundárias (roxa, laranja e verde), todas as peças confeccionadas com E.V.A.

A partir disto, no quarto momento da aplicação, a professora questiona as crianças, de maneira instigante e em linguagem adequada para a faixa etária: "de quantas maneiras diferentes o (a) boneco (a) poderá vir vestido à escola amanhã’?

O quinto momento consistiu em espaço e tempo para as crianças explorarem os materiais e "vestir" o (a) boneco (a) com todas as opções do vestuário (Figura 3), quantas vezes elas quisessem. Após esta manipulação dos materiais, as crianças efetuaram registros de cada uma das possibilidades em uma folha, conforme ilustrado na Figura 4 e a professora as auxiliou em registrar e manipular as mesmas informações em uma tabela de dupla entrada, representada na Figura 5. 


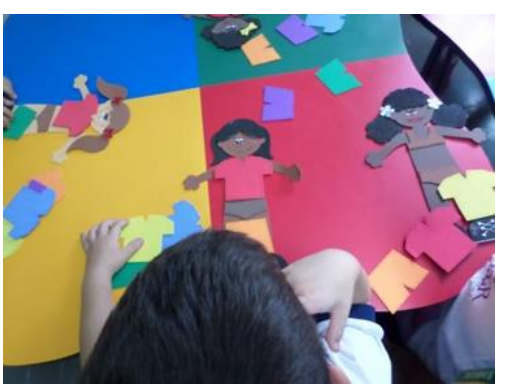

Figura 3 - Exploração do vestuário Fonte: Dados da Pesquisa, 2018.

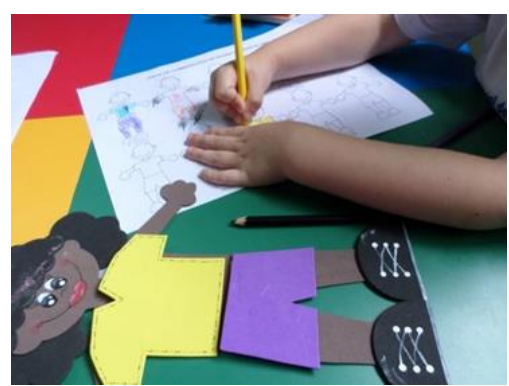

Figura 4 - Registro de combinações Fonte: Dados da Pesquisa, 2018.

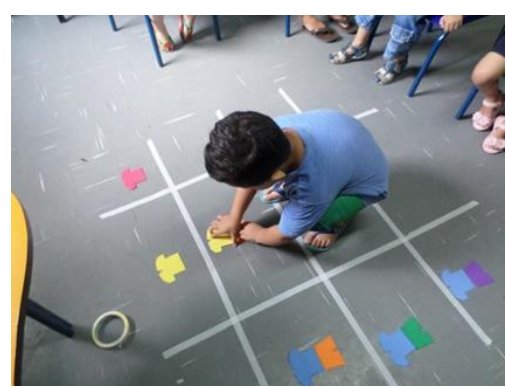

Figura 5 - Construção da tabela Fonte: Dados da pesquisa, 2018.

No último momento da aplicação, a professora explorou outras situações de aprendizagem, tanto dentro do mesmo conteúdo, quanto alcançando outras áreas do saber. Os materiais utilizados na aplicação foram úteis para a professora trabalhar em sala de aula habilidades além da Estocástica, como: conceito e importância do nome como substantivo próprio, coordenação motora fina (elaborou-se uma atividade na qual havia a necessidade de pendurar com um prendedor de roupas as camisetas e bermudas do (a) boneco (a)).

A partir desta aplicação, os dados considerados para análise foram: a narrativa da professora, fotos e vídeos curtos com alguns momentos das aulas. A análise dos dados foi realizada de acordo com a Análise Textual Discursiva (ATD), que, conforme Moraes e Galiazzi (2016, p. 13), é "uma metodologia de análise de informações de natureza qualitativa com a finalidade de produzir novas compreensões sobre os fenômenos e discursos". Conforme exige este tipo de análise, seguiu-se as etapas:

1) Leitura minuciosa de todos os dados, desconstruindo e fracionando para a identificação de unidades de análise. Nesta etapa voltou-se o olhar para a narrativa da professora, para o vídeo e para as fotos das aulas;

2) Processo de categorização, construindo relações entre os dados. As categorias deste estudo foram criadas a priori, de acordo com o referencial teórico em que está fundamentado, sendo relacionada com os dados após o primeiro contato com eles;

3) Compreensão dos dados, ou seja, a construção da Síntese Interpretativa que aponta o entendimento captado pelos pesquisadores. Após as fases de unitarização (leitura minuciosa) e de categorização, o texto de interpretação dos dados foi elaborado.

Assim, apresenta-se, na sequência, as categorias, subcategorias e unidades de análise, bem como a interpretação dos dados a partir da visão das pesquisadoras e da teoria de base deste estudo. Em um primeiro momento estão descritos os excertos a partir das unidades e categorias as quais pertencem e, na síntese interpretativa, há a relação entre as unidades de análise e o referencial teórico. 


\section{Análise dos dados}

Para esta análise, conforme apontado anteriormente, foram consideradas a narrativa da professora, a transcrição dos vídeos e as fotos da aplicação das atividades. As categorias, subcategorias e unidades de análise efetivadas, após o contato com os dados, estão organizadas no Quadro 1.

\begin{tabular}{|c|c|c|}
\hline Categorias: descrição & Subcategorias: & Unidades: descrição \\
\hline \multirow{3}{*}{$\begin{array}{l}\text { Categoria 1 (C1) - } \\
\text { Prática Pedagógica } \\
\text { como viabilizadora de } \\
\text { um ensino honesto. } \\
\text { Esta categoria agrupa as } \\
\text { unidades de análise que } \\
\text { dizem respeito à forma } \\
\text { de apresentação dos } \\
\text { conteúdos apresentados } \\
\text { às crianças, ou seja, } \\
\text { viabilizam, desta forma, } \\
\text { um ensino honesto, } \\
\text { conforme proposto por } \\
\text { Bruner }(1969,1987) \text {. }\end{array}$} & $\begin{array}{l}\text { (Não há subcategorias para } \\
\text { C1) }\end{array}$ & $\begin{array}{l}\text { Unidade } 1 \text { (U1) - Forma de representação. } \\
\text { Nesta unidade, C1.U1., incluem-se os excertos que } \\
\text { mostram indícios de que a forma como os conteúdos } \\
\text { foram abordados, na prática, estavam estruturados de } \\
\text { maneira adaptada a turma, ou seja, viabilizando um } \\
\text { ensino honesto. }\end{array}$ \\
\hline & & $\begin{array}{l}\text { Unidade } 2 \text { (U2) - Economia. } \\
\text { Na C1.U2. incluem-se os excertos que indicam que a } \\
\text { prática pedagógica possui um equilíbrio quanto a } \\
\text { quantidade de informações que deverão ser } \\
\text { processadas, ou seja, apresenta a quantidade ideal, } \\
\text { adaptada para a faixa etária das crianças em questão. }\end{array}$ \\
\hline & & $\begin{array}{l}\text { Unidade } 3 \text { (U3) - Potência efetiva. } \\
\text { Os excertos da C1.U3. indicam que o aluno foi capaz } \\
\text { de relacionar os assuntos apresentados e de enfrentar } \\
\text { os desafios intelectuais propostos, ou seja, de } \\
\text { responder ao problema apresentado. }\end{array}$ \\
\hline \multirow{5}{*}{$\begin{array}{l}\text { Categoria } 2(\mathrm{C} 2)- \\
\text { Prática pedagógica } \\
\text { como viabilizadora da } \\
\text { aprendizagem por } \\
\text { descoberta. } \\
\text { A C2 envolve as } \\
\text { subcategorias e unidades } \\
\text { que se voltam para a } \\
\text { prática pedagógica como } \\
\text { viabilizadora de uma } \\
\text { aprendizagem a partir de } \\
\text { descobertas. }\end{array}$} & $\begin{array}{l}\text { Subcategoria } 1(\mathrm{~S} 1)-\text { Desafio } \\
\text { para a criança. } \\
\text { A S1 subdivide a C2, pois se } \\
\text { refere às unidades focadas no } \\
\text { desafio para a criança como } \\
\text { propícias para a aprendizagem } \\
\text { por descoberta. }\end{array}$ & $\begin{array}{l}\text { Unidade } 1 \text { (U1) - Engloba toda e qualquer criança. } \\
\text { Aqui se fazem presentes os excertos (C2.S1.U1.) que } \\
\text { apontam a prática pedagógica como viabilizadora da } \\
\text { aprendizagem por descoberta, por conta do desafio } \\
\text { envolver toda e qualquer criança. }\end{array}$ \\
\hline & & $\begin{array}{l}\text { Unidade } 2(\mathrm{U} 2)-\text { Permite } 0 \text { avanço no } \\
\text { desenvolvimento. } \\
\text { Em C2.S1.U2. estão os excertos que refletem a prática } \\
\text { pedagógica como viabilizadora da aprendizagem por } \\
\text { descoberta, devido ao desafio de proporcionar } \\
\text { progressão no desenvolvimento da criança. }\end{array}$ \\
\hline & $\begin{array}{l}\text { Subcategoria } 2 \text { (S2) } \\
\text { Exploração de alternativas. } \\
\text { S2, segunda parte de C2, } \\
\text { refere-se a unidades focadas na } \\
\text { exploração de alternativas } \\
\text { como viabilizadora da } \\
\text { aprendizagem por descoberta. }\end{array}$ & $\begin{array}{l}\text { Unidade } 1 \text { (U1) - Ativação da exploração. } \\
\text { Os excertos de C2.S2.U1 representam situações em } \\
\text { que comprovam que o início da atividade despertou a } \\
\text { curiosidade. }\end{array}$ \\
\hline & & $\begin{array}{l}\text { Unidade } 2 \text { (U2) - Manutenção da exploração. } \\
\text { Esta unidade, C2.S2.U2, traz os excertos que indicam a } \\
\text { manutenção da exploração da atividade continuada por } \\
\text { meio do estímulo da professora. }\end{array}$ \\
\hline & & $\begin{array}{l}\text { Unidade } 3 \text { (U3) - Sentido da exploração. } \\
\text { Os excertos da C2.S2.U3 representam situações que } \\
\text { demonstram que a criança compreendeu o sentido } \\
\text { (motivo) de cada exploração visando o objetivo da } \\
\text { atividade. }\end{array}$ \\
\hline
\end{tabular}

Quadro 1 - Categorias, subcategorias e unidades de análise efetivadas

Fonte: Dados da Pesquisa, 2018. 
$\mathrm{Na}$ ATD, para a organização dos dados, se faz necessário codificar os excertos (trechos dos dados que foram categorizados). E, tendo em vista a origem de cada excerto, neste trabalho são usados os seguintes códigos para tratá-los: NP - para representar excertos extraídos da Narrativa da Professora; TV - para representar os excertos extraídos da transcrição do vídeo; F - para representar os excertos em formato de fotografias.

Deste modo, como exemplo de codificação de um excerto, pode-se citar: NP.L13.C1.U2 $2^{2}$ (Excerto da Narrativa da Professora, localizado na linha 13, categorizado na Categoria 1, Unidade 2); TV.TB.L89.C2.S1.U2 (Excerto da Transcrição do Vídeo, da Turma B, localizado na linha 89, categorizado na Categoria 2, Subcategoria 1 e Unidade 2); TV.TA.L81.C2.S1.U1 (Excerto da Transcrição do Vídeo, da Turma A, localizado na linha 81, categorizado na Categoria 2, Subcategoria 1 e Unidade 1); F4.TA.C2.S2.U3 (Excerto em forma de foto, registrado no computador das pesquisadoras como documento 4, da Turma A, categorizado na Categoria 2, Subcategoria 2 e Unidade 3) e F41.TB.C1.S2.U3 (Excerto em forma de foto, registrado no computador das pesquisadoras como documento 41, da Turma B, categorizado na Categoria 1, Subcategoria 2 e Unidade 3).

Para explicitar a ATD, efetuada sobre os dados coletados, apresenta-se em seguida, alguns dos excertos categorizados na C1.U1, pois, para explicitar cada unidade de análise, se fez necessário selecionar os considerados mais representativos. Na unidade 1 (C1), incluem-se os excertos que mostram indícios de que a forma como os conteúdos foram abordados na prática, e que estavam estruturados de maneira adaptada à turma, ou seja, viabilizando um ensino honesto.

Logo no início de sua narrativa, a professora aponta que a proposta estava em acordo com os documentos curriculares do município em que a prática foi aplicada:

A proposta pedagógica está de acordo com as Diretrizes Curriculares Municipais da cidade de Araucária, os conteúdos abordados estão presentes no rol de conteúdos para a turma de Infantil 4 e Infantil 5 (crianças de 3 a 5 anos), com nomenclatura diferente (NP.L1.C1.U1).

Deste modo, entende-se que os conteúdos abordados não estavam aquém do que se pede no currículo prescrito.

Além disso, os excertos abaixo sugerem uma apresentação de conceitos de forma honesta às crianças e reafirmam a estrutura adequada à faixa etária, pois representam acontecimentos característicos do universo infantil:

A estrutura estava adequada (NP.L6.C1.U1).

\footnotetext{
${ }^{2}$ A codificação, nesta pesquisa, será sempre separada por ponto (.)
} 
[...] todos os dias as crianças tinham interesse em saber sobre a boneca, como ela iria se vestir, mostraram-se preocupadas quando esfriou e ela não tinha calça e blusa para colocar (NP.L37.C1.U1).

Entretanto, foi possível notar que a prática poderia ter apresentado resultados mais promissores se tivesse sido apresentada em outro momento às crianças, pois:

[...] acredita-se que a abordagem seria mais relevante se proposta no segundo semestre do ano letivo, visto que as crianças estão no início do ano e muitas vezes a adaptação à sala de aula, às atividades e o desenvolvimento das crianças é mais propício no segundo semestre (NP.L7.C1.U1).

Este fato não impediu a realização das atividades propostas no plano, tampouco foi empecilho para que a professora abordasse outros conteúdos relacionados.

Na C1.U2. inclui-se os excertos que indicam que a prática pedagógica está adequada quanto a quantidade de informações que deverão ser processadas pelas crianças. No excerto abaixo, a professora torna claro que a quantidade de conteúdo apresentado para as crianças foi pertinente:

Em relação à quantidade de informação apresentou-se adequada às crianças, até mesmo porque mais informações foram acrescentadas, como mais conteúdos e atividades foram propostas além das que estavam no plano (NP.L11.C1.U2).

Nota-se, por exemplo, que a exploração alcançou, inclusive, outras áreas, pois:

[...] foi possivel explorar a importância do nome, da identidade, a identificação do nome, a identificação das cores por meio de brincadeiras com as roupinhas e outros objetos, também outro jogo foi proposto com dado no qual imagem de roupas em todos os lados e as crianças puderam desenvolver a coordenação motora fina, movimento de pinça para colocar as roupinhas em um varal de barbante (NP.L14.C1.U2).

O excerto representado na Figura 6 e 7, respectivamente (F25.TA.C1.U2) e (F31.TA.C1.U2), complementam esta unidade, pois expressam a diversidade de atividades que foram efetivadas.

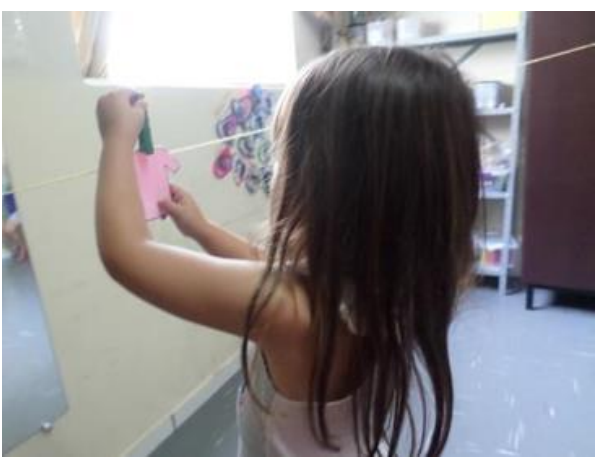

Figura 6 - F25.TA.C1.U2. Atividade para desenvolvimento da coordenação motora fina Fonte: Dados da Pesquisa, 2018.

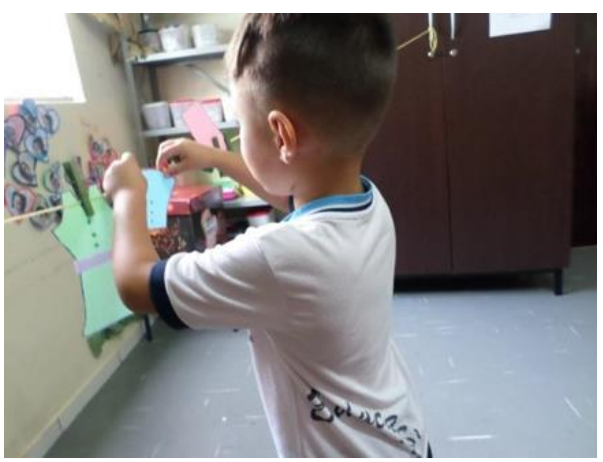

Figura 7 - F31.TA.C1.U2. Atividade para desenvolvimento da coordenação motora fina Fonte: Dados da Pesquisa, 2018.

Outro aspecto que aponta para o equilíbrio de quantidade de informação (C1.U2) é a 
conclusão da construção do gráfico de forma acessível e organizada pelas crianças, pois a professora aponta que "[....] participaram de maneira organizada da construção" (NP.88.C1.U2).

A professora, ainda, conseguiu organizar as atividades, propondo a exploração em diferentes momentos, reiterando que a quantidade de informações permitiu que as crianças explorassem o material e os conceitos envolvidos na prática:

Professora: ela pode trocar várias vezes de roupa. Hoje não vai dar tempo da gente fazer todas as combinações de roupa. A profe vai começar a montar lá no quadro as roupas que ela pode usar. E depois do lanche a profe vai deixar vocês brincarem com os bonequinhos que têm outros pra vocês trocarem de roupa neles, tá bom? A profe vai dando para cada um. Um grupo vai brincar com uma coisa e outro vai montando com a profe os bonequinhos. Combinado? Crianças: Combinado! (TV.TB.L71.C1.U2).

Os excertos da C1.U3. indicam que as crianças foram capazes de efetivar a relação entre os conteúdos e ainda dar resposta aos problemas sugeridos. Pelos excertos da C1.U3, nota-se que elas alcançaram êxito na leitura do gráfico e chegaram a conclusões sobre o nome da nova colega de classe (boneco (a)). De acordo com a professora:

[...] as crianças conseguiram responder aos questionamentos, compreenderam o gráfico, mencionando o nome vencedor (NP.L23.C1.U3).

Este aspecto também é confirmado pela conversa entre a professora e uma das crianças:

Professora: Mário $^{3}$, você acha que o nome que você escolheu foi o vencedor?

Mário: Hunhum.

Professora: Por que?

Mário: Porque ele é mais grande (apontando para o gráfico).

Professora: Maior né? Ele ficou maior, olha lá. Mais crianças escolheram. (TV. L38.C1.U3).

No excerto (TV.TB.L38.C1.U3) observa-se que a criança responde o questionamento realizado pela professora a partir da leitura do gráfico. Além disso:

$\mathrm{Na}$ construção da tabela na turma de Infantil 5, as crianças foram levando as roupas conforme eu ia solicitando relacionado a cor da bermuda e da camiseta (NP.L81.C1.U3).

Estes excertos mostram, então, que as crianças conseguiram enfrentar o desafio proposto e responderam ao problema levantado, fazendo uso das ferramentas estatísticas para chegar à conclusão do nome da nova colega e relacionando as trocas de roupas, realizadas na exploração do material, para a construção da tabela de dupla entrada.

As subcategorias e unidades de análise da C2 apresentam indícios da prática pedagógica como viabilizadora de uma aprendizagem a partir de descobertas. A C2.S1.U1

\footnotetext{
${ }^{3} \mathrm{O}$ nome foi alterado para garantir o anonimato da criança.
} 
aponta para o envolvimento de toda e qualquer criança na atividade. Isso é percebido na narrativa da professora quando afirma sobre a adequação efetuada para que todos pudessem participar da construção do gráfico e ainda pelo fato de atender a cada criança no momento em que as chamava para a troca de roupas na boneca:

[...] as crianças foram sendo chamadas individualmente, trocavam a roupa da Leo e registravam na folha de atividade (NP.L69.C2.S1.U1).

Além disso, a professora relata que:

[...] apenas uma das crianças não conseguiu pegar a cor de acordo com a roupa escolhida, então a professora chamou um colega para ajudar (NP.L78.C2.S1.U1).

Com isto, é possível perceber que o número de crianças que teve dificuldade para relacionar a cor da roupa com a do lápis para o registro da combinação é mínimo, e, mesmo assim, houve a intervenção para que a criança conseguisse completar a atividade.

Outro excerto que ilustra a adequação da proposta para toda e qualquer criança é a fala da professora ao explicar a dinâmica da atividade de construção do gráfico:

Professora: então a gente tem os três nomes e agora a gente vai fazer um gráfico pra gente ver qual nome que foi escolhido pra nossa amiga nova da nossa turma. Vamos lá então? Vamos construir o nosso gráfico? A profe vai desenhar lá no quadro e vai mandando vir, tá? (TV.TA.L81.C2.S1.U1)

Por meio do excerto TV.TA.L81.C2.S1.U1, pode-se perceber que todas as crianças experienciaram a mesma oportunidade no momento de construir o gráfico, toda criança pôde registrar seu voto e participar da construção do gráfico.

Os excertos da C2.S1.U2. dão indícios de que a prática proposta viabilizou a aprendizagem por descoberta, proporcionando a progressão no desenvolvimento da criança. A professora menciona isso em sua narrativa, apontando que:

Certamente é visivel o avanço no desenvolvimento das crianças com a prática pedagógica proposta (NP.L35.C2.S1.U2).

Em outro ponto da narrativa a professora menciona:

[...] em um momento de outro jogo sobre esquema corporal, primeiro questionamento foi sobre o nome do boneco e já mostraram-se interessados em escolher um nome (NP.L39.C2.S1.U2).

Este excerto mostra que as crianças foram capazes de relacionar o trabalho realizado anteriormente com outra situação, o que indica o desenvolvimento cognitivo. Esta característica pode ser observada também no excerto a seguir:

[...] com o clima eu fazia um desenho ao seu redor conforme as crianças iam expondo, se estava calor mencionavam: faz um sol, faz um picolé para a Leo (nome escolhido) faz um guarda-chuva, etc.(NP.L42.C2.S1.U2). 
A questão das roupas a serem utilizadas pelo(a) boneco(a) de acordo com a temperatura mostram um avanço na percepção das crianças sobre o clima, que inclusive não fazia parte do conteúdo programático.

A C2.S2.U1 trata da ativação para a exploração de alternativas, proposta na prática desenvolvida. Assim, os excertos comprovam o despertar da curiosidade das crianças, como se pode observar:

Para dar início às atividades propostas no plano de aula, em roda de conversa questionei se todos tinham nome e porque era importante ter um nome, foi feita a leitura da história do nome das crianças, atividade enviada às famílias, para posteriormente apresentar a boneca e falar que ela não tinha um nome, e lancei a proposta: vamos escolher um nome para ela? (NP.L48.C2.S2.U1).

Nesta proposta a professora lançou a problemática e, também, instigou as crianças para que, assim como eles, a nova colega pudesse ter um nome.

Após isso, a professora relata:

As crianças começaram a falar e fui colocando tudo no quadro (NP.L53.C2.S2.U1).

Isto sugere que as crianças estavam motivadas e curiosas para a escolha do nome e para a exploração da atividade proposta. O que é confirmado pela avaliação da professora sobre a forma como apresentou a atividade às crianças:

O desafio inicial da apresentação da nova colega da turma, foi bem relevante, principalmente na escolha do nome, as crianças opinaram com entusiasmo, mostraram interesse em conhecer e dar um nome para a boneca de EVA, principalmente porque já havia iniciado o trabalho sobre o nome, a importância de ter um nome, a história do nome de cada criança da turma (NP.L30.C2.S2.U1).

Nos excertos que compõem a C2.S2.U2. constata-se que houve uma manutenção da exploração da atividade efetivada por meio da ação da professora, viabilizando a aprendizagem por descoberta. O excerto abaixo comprova a exploração continuada da atividade e do material manipulado pelas crianças, com a intervenção da professora.

Discutiram sobre as trocas de roupas, querendo muitas vezes colocar a roupa igual a que o colega colocou, fizeram tentativas para não repetir a roupa, com mediação da professora (NP.L27.C2.S2.U2)

Especificamente sobre a viabilização da aprendizagem relacionada com esta manutenção da exploração, tem-se que

A maioria das crianças conseguiu compreender a proposta quando a professora mencionava ela já usou essa roupa e mostrava na folha impressa logo pegavam outra cor de bermuda ou camiseta (NP.L73.C2.S2.U2)

E ainda que

[...] durante todo o processo as crianças exploraram os materiais, mostraram-se interessadas em trocar as roupas bem como queriam que a professora colocasse a roupa que escolheram 
(NP.L90.C2.S2.U2).

$\mathrm{Na}$ C2.S2.U3, que se refere à compreensão da criança quanto ao significado da exploração visando o objetivo da atividade, tem-se no excerto TV.TB.L5.C2.S2.U3 a constatação desse entendimento, pois mostra que a criança percebeu a necessidade de todos terem votado em algum nome, construir o gráfico, interpretar o gráfico, e por fim solucionar um dos problemas da atividade (escolher um nome para o boneco (a)):

Professora: (direcionando a fala para umas das crianças da turma) Qual foi o nome que você escolheu para nossa amiga?

Aluna 1: Leo.

Professora: E é o nome vencedor?

Aluna 1: (balança cabeça em sinal de concordância).

Professora: Por que? Por que é o vencedor? Por que você acha que é o vencedor?

Aluna 1: Porque todo mundo escolheu.

Professora: Porque todo mundo escolheu. Muito bem”! (TV.TB.L5.C2.S2.U3)

Em (F45.TA.C2.S2.U3) e (F41.TB.C1.S2.U3) observa-se o registro realizado pelas crianças a respeito das combinações de vestuário (camiseta e bermuda). Após a exploração com os materiais em EVA, as crianças registraram as possibilidades, dando uma resposta ao problema das combinações que seriam possíveis. Estes excertos, também categorizados em C1.S2.U3, demonstram que as crianças compreenderam o significado da manipulação.

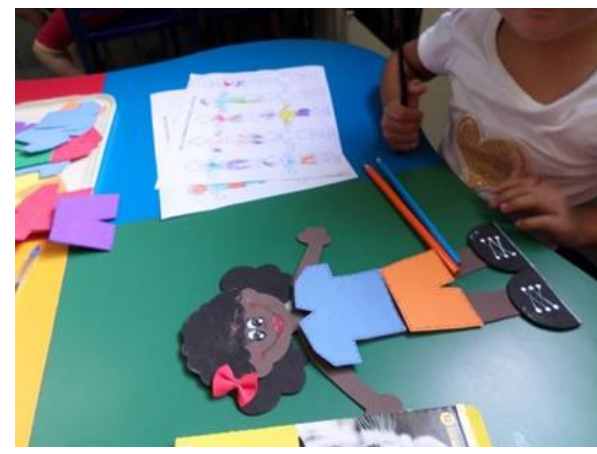

Figura 8 - F45.TA.C2.S2.U3. Registro das combinações de vestuário Fonte: Dados da pesquisa, 2018.

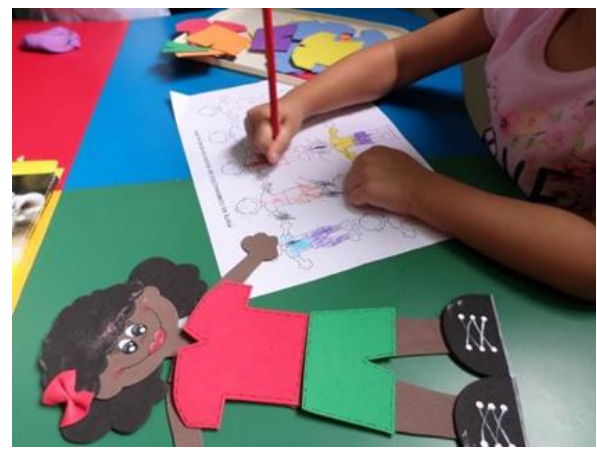

Figura 9 - F41.TB.C1.S2.U3. Registro das combinações de vestuário Fonte: Dados da pesquisa, 2018.

Visando a compreensão destes excertos, a partir da interpretação captada pelas pesquisadoras, apresenta-se, na sequência, o texto de Síntese Interpretativa.

\subsection{Síntese interpretativa}

A Categoria 1, que teve como foco a análise da prática pedagógica como viabilizadora de um ensino honesto, efetivou por meio das unidades, a presença de características da teoria de ensino de Bruner. A primeira delas está em C1.U1, a qual demonstrou que a prática 
pedagógica proposta trouxe uma estrutura adequada, apresentada na versão apropriada para as crianças da Educação Infantil e visando o modo em que elas veem o meio ao seu redor (BRUNER, 1969, 1987).

Além disto, a proposta atendeu às DCMA, que destacam a necessidade da adequação estrutural dos conteúdos para essa etapa escolar, pois as práticas precisam ser atrativas e adequadas para a realidade das crianças (ARAUCÁRIA, 2012).

Por meio da C1.U2 foi possível certificar a adequação quanto a quantidade de informações que as crianças precisariam processar. Para Bruner (1969) a economia (termo utilizado pelo autor para tratar a quantidade ideal a ser processada pelos alunos) permite o avanço gradativo no processamento da informação, priorizando o ensino e a aprendizagem. Na DCMA há menção de que os conteúdos relacionados à Estocástica devem ser tratados de maneira introdutória, de modo que se possibilite o aprofundamento posterior (ARAUCÁRIA, 2012), o que condiz com o currículo espiral da teoria de Bruner (1969).

Sobre a ideia de espiral, a professora destacou em sua narrativa que, se a atividade fosse reaplicada no final do ano, provavelmente haveria melhores resultados. Essa percepção é aceita pelas ideias da teoria de ensino, abordada nesta pesquisa, que sugere que os conceitos sejam retomados em diversos momentos e no decorrer da escolaridade. Ademais, reitera o que aponta Borba (2016), ao afirmar que, já na etapa da Educação Infantil, algumas noções e construções mais simples de conceitos podem ser abordadas em práticas concretas e lúdicas.

A C1.U3 constatou a presença de potência efetiva, visto que as crianças foram capazes de responder aos problemas propostos e capazes de aplicar os conhecimentos relacionando com outros assuntos (BRUNNER, 1969, 1987), o que sugere que a prática proporcionou condições para que as crianças compreendam com o mundo que as rodeia, oportunizando o envolvimento na construção de ferramentas estatísticas, para organizarem informações por elas coletadas (NOGUEIRA; MARQUES, 2016).

Neste sentido, reafirma-se a possibilidade das crianças serem estimuladas ao trabalho “de investigação e como informações podem ser levantadas, organizadas, classificadas e interpretadas, bem como podem ser incentivadas a refletirem sobre como eventos ocorrem" (BORBA, 2016, p. 2). Atrelado a essa possibilidade, é possível trabalhar com os conteúdos Estocásticos na Educação Infantil, permitindo a vivência de representação e análise de dados, conforme recomendado por Lopes (2012).

A Categoria 2, que apontou a prática pedagógica como viabilizadora da aprendizagem por descoberta, foi subdividida em 2 subcategorias, a primeira voltada ao desafio para a criança, como viabilizadora, e a segunda, priorizando aprendizagem a partir da exploração. A 
primeira unidade de S1, que mostrou o envolvimento de toda e qualquer criança no desafio, relaciona-se com a ideia de Bruner, quanto a não enxergar a individualidade dos alunos como um obstáculo para envolver a todos, e sim como um argumento a favor da diversidade de metodologias e de apresentação dos conteúdos (BRUNER, 1969), no caso desta aplicação, os conteúdos Estocásticos.

Fonseca e Estevam (2014) contribuem com esta questão da diversificação das tarefas e métodos de ensino, pois, para eles, a prática deve priorizar interação, atendendo as crianças em momentos grupais e individuais. Conforme se mostra nos excertos, a professora realizou práticas que atenderam a todas as crianças, em momentos coletivos e individuais.

A segunda unidade de S1 trata do avanço no desenvolvimento da criança a partir do desafio, viabilizando a aprendizagem por descoberta. Quanto a este avanço, Bruner (1969) destaca que ensinar conceitos é auxiliar as crianças a passarem progressivamente das formas de representações concretas para as mais abstratas. Ademais, quanto mais cedo a criança tem contato com conceitos relacionados à Estocástica, mais chances têm de fazer reflexões e de pensar sobre suas ideias, avançando nos modos de raciocínio (BORBA, 2016).

As unidades da S2 refletem a aprendizagem por descoberta por meio da exploração de alternativas, o que é perceptível nos excertos. A efetivação ocorreu nos três aspectos representados por cada uma das unidades: ativação, manutenção e sentido. Percebeu-se que a professora conseguiu instigar a curiosidade dos alunos, direcionar o andamento da atividade $\mathrm{e}$ significar cada exploração. Bruner (1969) afirma que a aprendizagem por descoberta, viabilizada pela exploração de alternativas, necessita de um início (ativação), de um efeito para manter a criança em ação (manutenção) e de um sentido, evitando que se perca ao acaso.

A prática desenvolvida, como se observa nos excertos, viabilizou momentos de exploração de alternativas e, ainda, proporcionou o avanço nas formas de representação, pois, partiu de materiais manipuláveis (boneco(a) e vestuário, fichas do gráfico) para depois seguir para a representação em imagens do conceito (folha de registro das combinações) e, por fim, para a representação simbólica (contagem dos votos/leitura do gráfico e contagem das combinações possíveis). Isto sugere que houve a oportunidade de avanço da representação ativa para a icônica e para a simbólica, aspecto apontado por Bruner $(1969,1987)$ como fundamentais para as práticas de ensino.

A partir da efetivação das categorias foi possível notar o que Lopes (2012) enfatiza sobre a aprendizagem da criança, que tem início a partir de brincadeiras que permitem a construção de significados, de comunicação, tomada de decisões, decodificação de regras, expressões linguísticas e de socialização. Notou-se ainda que as atividades com os conteúdos 
estocásticos respeitaram o universo infantil e proporcionaram a exploração de caminhos para a construção do conhecimento, conforme destaca Bruner (1969).

\section{Considerações finais}

O propósito deste artigo foi analisar as contribuições de uma prática pedagógica elaborada para ensinar Estocástica às crianças da Educação Infantil, com respaldo na teoria de ensino de Bruner. Como se observa na descrição e na ATD realizada sobre os dados, houve indícios de avanço no desenvolvimento intelectual das crianças, possibilidade de aprendizagem por descoberta, atendimento de todos os alunos nas práticas desenvolvidas, formação de conceitos estocásticos na base da escolarização para o aprofundamento em etapas posteriores, entre outras.

Foi possível, ainda, perceber a relevância do estudo da temática, englobando formas diferentes de representação, passando-se das ações (ativa) para imagens (icônica) e, por fim, para a codificação (simbólica). Estes aspectos reiteram a viabilidade da teoria de Bruner para a construção e análise de propostas de ensino voltadas à Estocástica.

Sobre o questionamento indicado no título deste artigo, pode-se dizer que há uma versão adequada de conceitos estocásticos para ensinar às crianças da Educação Infantil, mesmo que isso se dê de forma introdutória. Porém, é importante que o estudo dos conceitos seja retomado, como ficou evidente na narrativa da professora e, também, como sugere Bruner $(1969,1987)$. Na retomada as crianças terão oportunidade de revisitar conceitos e de construir uma base sólida de conhecimentos, que serão úteis para sua vivência, viabilizando um currículo em espiral.

\section{Agradecimentos}

Este trabalho foi realizado com apoio da Capes (Código de Financiamento 001).

\section{Referências}

ARAUCÁRIA. Diretrizes municipais de educação. Prefeitura do Município de Araucária. Secretaria Municipal de Educação, 2012. 347 p.

BORBA, Rute. Antes que seja tarde: aprendendo Combinatória desde o início da escolarização. Em Teia - Revista de Educação Matemática e Tecnológica Iberoamericana, Recife, v. 7, n. 1, p. 1- 17, 2016. Disponível em: https://bit.ly/30bTESC. Acesso em: 9 dez. 2016. 
BRASIL. Base nacional comum curricular. Ministério da Educação, 2017. 472 p.

BRUNER, Jerone S. Uma nova teoria de aprendizagem. Rio de Janeiro: Bloch, 1969.

BRUNER, Jerone.S. O processo da educação. São Paulo: Nacional, 1987.

FONSECA, Alessandra da; ESTEVAM, Everton. Estocástica na educação infantil: discussões e reflexões acerca da probabilidade e estatística na infância. In: ENCONTRO PARANAENSE DE EDUCAÇÃO MATEMÁTICA - XII EPREM, 12, 2014, Campo Mourão. Anais... Campo Mourão, 2014. p 1-12. Disponível em: https://bit.ly/2PPXvQu. Acesso em: 16 jan. 2018.

LOPES, Celi Espasandin. A educação estocástica na infầncia. Revista Eletrônica de Educação, São Carlos, v. 6, n. 1, p. 160-74, 2012. Disponível em: https://bit.ly/304bmHC. Acesso em: 6 fev. 2018.

MORAES, Roque; GALIAZZI, Maria do Carmo. Análise Textual Discursiva. 3. ed. Ijuí: Editora Unijuí, 2016.

NOGUEIRA, Rosicléia Martins; MARQUES, Valéria Risuenho. Entre rios e saberes: trabalhando gráficos e tabelas em turma de educação infantil. In: ENCONTRO DE COMBINATÓRIA, ESTATÍSTICA E PROBABILIDADE DOS ANOS INICIAIS - ENCEPAI, 1, 2016, Recife. Anais... Recife, 2016. p. 1-10. Disponível em: https://bit.ly/2H9VB9c. Acesso em: 10 fev. 2018.

PEREIRA, Caroline Subirá. Material manipulável e manipulável virtual para o ensino de estimativa de proporção populacional na formação inicial de professores. $91 \mathrm{f}$. Dissertação. (Mestrado Profissional em Ensino de Ciência e Tecnologia). Universidade Tecnológica Federal do Paraná, Ponta Grossa, 2017.

SILVEIRA, Denise Tolfo; CÓRDOVA, Fernanda Peixoto. A pesquisa científica. In: GERHARDT, Tatiana Engel; SILVEIRA, Denise Tolfo (Org.). Métodos de Pesquisa. Porto Alegre: Editora UFRGS, 2009. p. 31-42.

Submetido em 07 de Maio de 2019. Aprovado em 30 de Setembro de 2019. 